Chapman University

Chapman University Digital Commons

3-23-2018

\title{
Goal Setting in the Principal-Agent Model: Weak Incentives for Strong Performance
}

Brice Corgnet

Joaquín Gómez-Miñambres

Roberto Hernán-González

Follow this and additional works at: https://digitalcommons.chapman.edu/esi_pubs

Part of the Economic Theory Commons, and the Other Economics Commons 


\section{Goal Setting in the Principal-Agent Model: Weak Incentives for Strong Performance}

\section{Comments}

NOTICE: this is the author's version of a work that was accepted for publication in Games and Economic Behavior. Changes resulting from the publishing process, such as peer review, editing, corrections, structural formatting, and other quality control mechanisms may not be reflected in this document. Changes may have been made to this work since it was submitted for publication. A definitive version was subsequently published in Games and Economic Behavior, volume 109, in 2018. DOI: 10.1016/j.geb.2017.12.017

The Creative Commons license below applies only to this version of the article.

\section{Creative Commons License}

\section{(c) 1 (1) 90}

This work is licensed under a Creative Commons Attribution-Noncommercial-No Derivative Works 4.0 License.

\section{Copyright}

Elsevier 


\title{
Goal Setting in the Principal-Agent Model: Weak Incentives for Strong Performance
}

\author{
Brice Corgnet, Joaquín Gómez-Miñambres and Roberto Hernán-Gonzalez ${ }^{1}$
}

\begin{abstract}
We study a principal-agent framework in which principals can assign wage-irrelevant goals to agents. We find evidence that, when given the possibility to set wage-irrelevant goals, principals select incentive contracts for which pay is less responsive to agents' performance. Agents' performance is higher in the presence of goal setting despite weaker incentives. We develop a principal-agent model with reference-dependent utility that illustrates how labor contracts combining weak monetary incentives and wage-irrelevant goals can be optimal. The pervasive use of non-monetary incentives in the workplace may help account for previous empirical findings suggesting that firms rely on unexpectedly weak monetary incentives.
\end{abstract}

KEYWORDS: Principal-agent models, incentive theory, non-monetary incentives, goal setting, reference-dependent utility, laboratory experiments.

JEL CODES: C92, D23, M54.

\footnotetext{
${ }^{1}$ Brice Corgnet: Chapman University, George L. Argyros School of Business and Economics. One University Drive, Orange, California 92866. Chapman University, Economic Science Institute. One University Drive, Orange, California 92866. Email: corgnet(at)chapman.edu. Joaquín Gómez-Miñambres: Bucknell University, Department of Economics, One Dent Drive, Lewisburg, PA 17837. Chapman University, Economic Science Institute. One University Drive, Orange, California 92866. Email: jgm023(at)bucknell.edu Roberto Hernán-Gonzalez: Nottingham University, Business School, Nottingham, UK, Email: Roberto.HernanGonzalez(at)nottingham.ac.uk.
} 


\section{INTRODUCTION}

\subsection{Monetary and Non-monetary Incentives}

Contract theory has traditionally focused on the design of monetary incentives as the unique motivation tool. The premise of these theories, also known as the principal-agent paradigm, is that workers will only respond to monetary incentives (e.g. piece rates, bonuses, stock options) leaving aside the role of intrinsic motivators (see Laffont and Martimort, 2002 and Bolton and Dewatripont, 2005 for reviews). These theories commend a widespread use of monetary incentives rewarding workers according to observable measures of effort. The predictions of these models, however, are frequently at odds with observed labor contracts. One of the major puzzles for this literature is to account for the rather limited use of monetary incentives in the workplace. For example, Chiappori and Salanié (2000) report extensive evidence that pay is much less sensitive to firm performance than what standard theories predict.

In this paper, we put forward that this discrepancy between theory and evidence may result from principal-agent models neglecting important aspects of work motivation related to the use of non-monetary incentives. Psychologists and behavioral economists (Deci 1971, 1975; Frey and Jegen, 2001) have already challenged the idea that workers' motivation relies exclusively on monetary incentives. For example, self-determination theory (Deci and Ryan, 1985; Ryan and Deci, 2000) posits a continuum of motivational states ranging from extrinsic motivation, in which people are motivated by external factors, to intrinsic motivation, in which their behavior is completely self-determined. In the workplace, intrinsic motivation is associated with high levels of employee satisfaction, commitment, and wellbeing (e.g., Baard et al. 2004; Deci et al. 2001). Self-determination theory suggests that intrinsic motives may alleviate the conflict of interest between workers who supposedly dislike effort and employers who aim at maximizing firm performance. This theory also explains why higher extrinsic incentives (e.g. monetary incentives or managerial control) may undermine workers' internal drives (see Gneezy et al. 2011 and Kamenica, 2012 for reviews).

Even though a growing number of works in Economics have documented the effectiveness of various forms of non-monetary incentives such as goals (Wu et al. 2008; Goerg and Kube, 2012; Gómez-Miñambres, 2012; Corgnet et al. 2015a; Dalton et al. 2015; van Lent and Souverijny, 2015; Allen et al. 2016), status incentives (Charness et al. 2014), symbolic rewards (Kosfeld and Neckermann, 2011), delegation (Fehr et al. 2013), autonomy (Falk and Kosfeld, 2006) or trust (Dickinson and Villeval, 2008), little is known about the interaction between monetary and non- 
monetary incentives. It is essential, however, to examine monetary and non-monetary incentives jointly to provide guidance for practitioners who typically use both types of incentives.

\subsection{Contract Design and Non-monetary Incentives}

Our approach aims at incorporating non-monetary incentives in the principal-agent framework by relying on the widespread and extensively-studied practice of "goal setting". The motivational effect of wage-irrelevant goals has been studied at length in the literature in Psychology and Management (see Locke, 1996 and Locke and Latham, 2002 for reviews) and more recently in the Economics literature (Wu et al. 2008; Goerg and Kube, 2012; GómezMiñambres, 2012; Corgnet et al. 2015a). According to Locke and Latham (2002) 90\% of the studies show a positive correlation between the use of goal setting in firms and workers performance. The literature has, however, paid little attention to the study of the relationship between wage-irrelevant goals and monetary incentives which seems essential to both incentive theorists and practitioners.

Corgnet et al. (2015a) took a first step in that direction by studying the interaction between monetary stakes and goal setting policies. They showed that goals tend to be more effective when stakes are large than when they are small. The present work goes one step further by studying the design of contracts that include both monetary incentives and wage-irrelevant goals.

From a theoretical standpoint, we modify the standard principal-agent model with moral hazard (e.g. Holmström, 1979) by assuming that the agent has two sources of work motivation: a standard monetary motivation and a goal-dependent non-monetary motivation. As a result, workers' utility not only increases when pay is high but also when goals are achieved. Extending on Kahneman and Tversky (1979) we assume that agents are loss averse in the non-monetary domain. In our model, this implies that the utility loss of falling short of the goal by a certain amount is higher than the utility gain of producing more than the goal by the same amount. Our theoretical contribution is to extend the principal-agent model to a case in which principals can set both monetary (a fixed pay and a performance pay) and non-monetary incentives (wageirrelevant goals). We show that goal setting, by providing an additional tool to incentivize agents, allows principals to achieve stronger incentives while making lesser use of performance pay. One caveat with the use of goal setting is that agents will suffer a utility loss if they do not attain the goal set by the principal. To compensate for that possibility, the principal will increase the agent's fixed pay when setting goals to agents. Therefore, goal setting generates a tradeoff between lowering performance pay and increasing fixed pay to ensure agents' participation. The 
optimal contract is such that the decrease in performance pay made possible by the use of wageirrelevant goals more than compensates the necessary increase in fixed pay, thus reducing the principal's agency costs to motivate agents. Therefore, agents will exert more effort and principals will obtain higher earnings when goal setting is present in the model. In the presence of goal setting, the principal will thus be able to reduce the wage bill by substituting costly monetary incentives with non-monetary incentives.

In our setting, optimal contracts typically rely both on performance pay and wage-irrelevant goals. Our framework contrasts with models in which monetary incentives may undermine intrinsic motivation. For example, Bénabou and Tirole (2003) stress the possibly negative effect of monetary incentives on agents' intrinsic motivation in a setting in which an informed principal holds private information about the agent's ability level. In their model, the crowding out of intrinsic motivation arises because setting strong monetary incentives provides a negative signal on the agent's ability level which, in turn, may lead the agent to exert low effort. By contrast, our model considers the commonly-studied case in which agents (not principals) hold private information about their level of ability. In that case, performance pay does not signal low-ability to the agent and thus does not undermine motivation.

We test our model conjectures using a controlled experimental environment in which we recreate the essence of a principal-agent model with goal setting. We isolate the effect of nonmonetary incentives (goal setting) by comparing contract design and organizational production in two separate environments: one in which goal setting is available to the principal and one in which it is not. To that end, we use a virtual workplace that reproduces features of existing organizations such as real-effort tasks and on-the-job leisure (Internet browsing) (Corgnet et al. 2015a). This real-effort and real-leisure work environment has been shown to be suited for the study of labor incentives in the laboratory (Corgnet et al. 2015b, 2015c, 2015d). In our setting, the principal selects a wage-irrelevant goal in addition to monetary incentives which include both a fixed pay and a performance pay, where performance pay states the share of total output assigned to the agent as in standard linear incentive contracts. The agent then decides whether to accept or reject the principal's offer. In line with our theoretical conjectures, we show that goals were effectively used by principals to motivate agents. Principals decided to set a goal in $84.5 \%$ of the cases in which they were allowed to do so, in addition to setting monetary incentives. We confirm the prediction of our theoretical model regarding compensation contracts by showing that principals set weaker monetary incentives in the presence of goals than in their absence. In 
particular, performance (fixed) pay for the contracts accepted by the agent was on average equal to $40.4 \%(104.9 \phi)$ of total output in the presence of goals compared to $45.1 \%(98.7 \not)$ in the absence of goals. Despite weaker incentives and in line with our model predictions, agents worked significantly more $(28.1 \%$ more $)$ in the presence of goals than in their absence. Consistently, principals earned $17.3 \%$ more in the experimental design in which they were allowed to set goals.

\subsection{Related Literature on Contract Design with Reference-dependent Utility Functions}

The specification of our goal setting model is motivated by the experimental evidence in Heath et al. (1999) showing that goals serve as reference points consistently with prospect theory (Kahneman and Tversky, 1979). Our approach thus relates to the works studying optimal contracting in the presence of prospect theory preferences. In the Finance literature, Dittman et al. (2010) analyze optimal executive compensation contracts when CEOs are loss averse. The authors consider a typical CEO compensation contract with fixed wages, stocks and options. Stocks are riskier than options but provide stronger incentives because they are more tightly linked to the actual value of the firm. They show that in a standard principal-agent model without loss aversion the incentive effect dominates the risk-tolerance effect so that the optimal contract should only involve stocks, a result which is inconsistent with observed CEO contracts. The authors also show that their principal-agent model can be reconciled with empirical evidence when assuming that CEOs are loss averse. In that case, options become part and parcel of the optimal contract because they provide insurance to CEOs against losses in case of bad luck. Relatedly, de Meza and Webb (2007) argue that compensation contracts including bonuses may be optimal when agents are loss averse with respect to a reference wage. The authors consider the reference point to be either exogenous or given by the median of possible wages. Herweg et al. (2010) consider a principal-agent model where the reference wage of the agent is determined by rational expectations following Köszegi and Rabin (2006). The results in Herweg et al. (2010) are consistent with de Meza and Webb (2007) as they show that bonus contracts are likely to be optimal when agents are loss averse. In line with previous research, our model considers a principal-agent framework in which the agent's utility function is reference dependent. Unlike previous papers, however, we study optimal contract setting in an environment in which principals set both monetary and non-monetary incentives (wage-irrelevant goals). In our setting, goals act as reference points for agents' intrinsic motivation. We thus focus on the case in which agents are loss averse in the non-monetary domain rather than in the monetary domain. 
The paper proceeds as follows. In Section 2 we introduce our theoretical framework. Section 3 describes the experimental environment, procedures and hypotheses. Main results are exposed in Section 4. Section 5 concludes.

\section{THEORETICAL FRAMEWORK}

In this section, we develop a principal-agent model in which wage-irrelevant goals act as reference points for the agent. This model will help us derive a set of conjectures which will be tested using experiments.

\subsection{The Model}

We consider a binary effort principal-agent model with moral hazard à la Laffont and Martimort (2002). There are two types of agents indexed by $i \in\{l, h\}$ where $l$ stands for low ability and $h$ stands for high ability. The principal does not observe the level of ability of the agent but knows the proportion $(\theta)$ of high-ability agents in the population. Effort is denoted by $e_{i} \in\{0,1\}$. Exerting effort implies a cost $c(e)$, where the cost of effort is normalized as follows: $c(0)=0$ and $c(1)=c$. Production $(y)$ is stochastic and can take three values $\left\{y_{0}, y_{L}, y_{H}\right\}$ where $y_{H}>y_{L}>y_{0}=0$. High-ability agents can produce $\left\{y_{L}, y_{H}\right\}$ while low-ability agents can produce $\left\{0, y_{L}\right\}$. Effort affects production following first order stochastic dominance so that $\operatorname{Pr}\left(y=y_{L} \mid e_{l}=0\right)=\operatorname{Pr}\left(y=y_{H} \mid e_{h}=0\right)=\pi_{0}, \quad$ and $\quad \operatorname{Pr}\left(y=y_{L} \mid e_{l}=1\right)=\operatorname{Pr}(y=$ $\left.y_{H} \mid e_{h}=1\right)=\pi_{1}$, with $\Delta \pi:=\pi_{1}-\pi_{0}>0$.

The agent is paid a wage $(w)$ from the principal according to a linear contract $w:=\alpha+\beta y$, where $\alpha$ represents fixed pay and $\beta \in[0,1]$ represents performance pay. We assume that $\alpha$ cannot be negative, so that the principal cannot "sell the firm" to the agent. This restriction implies limited liability of the agent.

The agent derives monetary utility, $u(\cdot)$, as well as non-monetary utility, $v(\cdot)$, which is obtained from attaining wage-irrelevant goals set by the principal. We assume that the agent's monetary utility function is $u(w)=w$. We define the agent's non-monetary utility as a reference-dependent function where the reference point is assumed to be a wage-irrelevant goal (g) which is set by the principal when proposing the contract to the agent. Our specification is motivated by lab and field evidence (Heath et al. 1999 and Allen et al. 2016) showing that wage- 
irrelevant goals serve as reference points in a manner which is consistent with prospect theory (Kahneman and Tversky, 1979). ${ }^{2}$

More specifically, the non-monetary utility function, for a particular goal $(g)$, is given by $v(y-g)$, where $v(\cdot)$ has the following properties:

(ii) $\quad v^{\prime}(\cdot)>0$ (increasing in production given a goal);

(iii) For all $x>0,-v(-x)=\lambda v(x)$ where $\lambda>1$ (goal-induced loss aversion);

(iv) $\quad v^{\prime \prime}(x)>0$ for all $x<0$ (convexity for goal-induced losses), and;

(v) $\quad v^{\prime \prime}(x)<0$ for all $x>0$ (concavity for goal-induced gains).

For convenience, we will denote $v_{j, g}:=v\left(y_{j}-g\right)$ and $\Delta v_{j k, g}:=v\left(y_{j}-g\right)-v\left(y_{k}-g\right)$ for $j, k \in\{0, L, H\}$. We denote by $U\left(w, y, e_{i}, g\right)$ the sum of monetary and non-monetary utility minus the cost of effort:

$$
U\left(w, y, e_{i}, g\right):=w+v(y-g)-c\left(e_{i}\right)
$$

Principals are assumed to be risk neutral thus maximizing expected profits which are defined as the difference between the agent's expected production and the agent expected wage. The principal's problem is thus to choose monetary incentives and goals that maximize expected profits subject to incentive compatibility and participation constraints. For the sake of illustration we will focus our attention on contracts that induce both low- and high- ability agents to exert effort. ${ }^{3}$

\subsection{Goal Setting and Monetary Incentives: The Optimal Labor Contract}

In Proposition 1 we characterize the optimal labor contract when principals set both monetary incentives $\{\alpha, \beta\}$ and non-monetary incentives $(g)$. Since the optimal labor contract is affected by the goal $(g)$ we refer to the optimal fixed pay for a given goal as $\alpha_{g}^{*}$ and the optimal performance pay for a given goal as $\beta_{g}^{*}$.

\footnotetext{
${ }^{2}$ This specification was also used in theoretical works such as Wu et al. (2008) who studied workers' response to exogenously given goals in the absence of monetary incentives.

${ }^{3}$ Similar findings hold when considering the case in which principals induce only one type of agent to exert effort. Further details are available upon request from the authors.
} 
Proposition 1 (Optimal contract with goal setting)

The optimal contract for a given goal is such that:

$$
\begin{gathered}
\alpha_{g}^{*}=\max \left\{-c \frac{\pi_{0}}{\Delta \pi}-\pi_{1}\left(\Delta v_{L 0, g}-\Delta v_{H L, g}\right)-v_{0 g}, 0\right\} \\
\beta_{g}^{*}=\max \left\{\frac{1}{\mathrm{y}_{H}-\mathrm{y}_{L}}\left[\frac{c}{\Delta \pi}-\Delta v_{H L, g}\right], 0\right\}
\end{gathered}
$$

And the optimal goal is such that:

$$
g^{*} \in\left(0, y_{H}\right)
$$

The principal uses performance pay to reward the agent when output is high. Performance pay $\left(\beta_{g}^{*}\right)$ increases with the cost of effort and decreases with $\Delta v_{H L, g}$ that represents the agent's goal-dependent utility of achieving a high output relative to a low output. Note that if this goaldependent non-monetary payoff is sufficiently high with respect to the cost of effort the principal will not need to provide any monetary incentives $\left(\beta_{g}^{*}=0\right)$ to motivate the agent. The fixed pay $\left(\alpha_{g}^{*}\right)$ is set so that the agent accepts the labor contract. Finally, the optimal goal $\left(g^{*}\right)$ is positive and always attainable by the high-ability agent.

In the following corollary we study the relationship between fixed pay, performance pay and goals in the optimal labor contract.

Corollary 1 (Monetary incentives and goals)

$$
\frac{d \alpha_{g}^{*}}{d g} \geq 0 ; \quad \frac{d \beta_{g}^{*}}{d g} \leq 0
$$

Corollary 1 captures an important effect of wage-irrelevant goals on the compensation contract. It shows that an increase in the goal set by the principal leads to an increase in fixed pay and a decrease in performance pay. In other words, goal setting makes the optimal contract less sensitive to changes in performance.

The intuition behind Corollary 1 follows from the fact that goals provide non-monetary incentives that can be used to substitute monetary incentives thus dampening the weight of performance pay in the labor contract. By setting appropriate goals which are less likely to be attained with low effort the principal can increase the non-monetary costs of shirking. Doing so, the principal will be able to decrease performance pay while still motivating the agent to work. Technically, the principal can choose goals that maximize $\Delta v_{H L, g}$ thus making the agent's incentive compatibility constraint slacker so that performance pay can be lowered while still motivating the agent to exert effort. However, using goals to motivate the agent comes at a cost. 
As principals set more challenging goals the agent is more likely to fall short of the goal and experience a non-monetary loss. It follows that principals who set challenging goals will have to raise fixed pay to ensure the participation of the agent. In sum, goal setting generates a tradeoff between lowering performance-based incentives and increasing fixed pay to ensure agents' participation.

Corollary 1 sheds light on previous empirical evidence regarding the relative weakness of incentives in real-world labor contracts (see Chiappori and Salanié 2000). In particular, we show that taking into account non-monetary incentives such as goal setting may be key to understand the limited use of monetary incentives in actual labor contracts.

An essential feature of the optimal contract is that the decrease in performance pay (monetary incentives) made possible by the use of wage-irrelevant goals (non-monetary incentives) more than compensates the necessary increase in fixed pay. This leads to a decrease in the principal's agency costs of motivating agents without decreasing the (monetary and non-monetary) incentives of the agent to exert effort. It follows that agents will exert more effort and principals will obtain higher earnings when goal setting is possible than when it is not $(g=0)$. We summarize these findings in our second corollary.

Corollary 2 (Goal setting minimizes agency costs) Goal setting allows the principal to induce agents to exert high effort with a lower wage bill.

The main implications of our model will be tested in a controlled workplace environment which is described in the next section.

\section{EXPERIMENTAL DESIGN \& CONJECTURES}

\subsection{Virtual Workplace with Real Effort and Real Leisure}

We develop a framework in which subjects can undertake a real-effort task while having access to a real-leisure alternative (browsing the Internet) at any point in time during the experiment. The idea is to consider a laboratory environment in which on-the-job shirking is commonly observed so as to be able to uncover incentives effects (Corgnet et al. 2015d). The laboratory setting allows the experimenter to control for possible confounding factors commonly 
encountered in the field such as organizational hierarchies or implicit incentives thus facilitating the detection of incentives effects. ${ }^{4}$

\subsubsection{Organizational Roles}

We consider two types of subjects referred to as B (agent) and C (principal). At the beginning of each of the 6 periods, subjects were randomly assigned to one of these two roles. As a result, subjects could either be an agent or a principal depending on the period. ${ }^{5}$ Each agent was randomly matched with a single principal. During a period, agents could dedicate their time to either completing the work task or browsing the web while principals could only browse the Internet.

\subsubsection{The Work Task}

We consider a real-effort summation task that is particularly long, laborious and effortful (e.g. Dohmen and Falk, 2011; Eriksson et al. 2009; Niederle and Vesterlund, 2007). Subjects would sum up matrices of 36 numbers comprised between 0 and 3 for one hour, divided into 10minute periods. Each table completed correctly generated a 40-cent profit while a penalty of 20 cents was subtracted from individual production for each incorrect answer. ${ }^{6}$ We define production as the monetary amount generated by a subject's answers on the work task.

Subjects were not allowed to use a pen, scratch paper or calculator. This rule amplified the level of effort subjects had to exert in order to complete tables correctly. An example of the work task is shown in Figure 1.

\begin{tabular}{|c|c|c|c|c|c|c|}
\hline & Column1 & Column2 & Column3 & Column4 & Column5 & Column6 \\
\cline { 2 - 7 } & 3.00 & 0.00 & 0.00 & 2.00 & 3.00 & 0.00 \\
\hline & 2.00 & 3.00 & 3.00 & 2.00 & 1.00 & 0.00 \\
\hline & 1.00 & 1.00 & 2.00 & 0.00 & 1.00 & 1.00 \\
\hline & 3.00 & 0.00 & 0.00 & 1.00 & 2.00 & 2.00 \\
\hline & 1.00 & 3.00 & 0.00 & 3.00 & 1.00 & \\
\hline & 1.00 & 3.00 & 1.00 & 1.00 & & \\
\hline
\end{tabular}

FIGURE 1.- Example of table summation for the work task.

\footnotetext{
${ }^{4}$ In our lab setting, agents only face explicit incentives.

${ }^{5}$ In a similar environment, Corgnet et al. (2015a) find that fixing subjects' roles for the whole experiment instead of randomizing roles each period does not significantly affect behavior.

${ }^{6}$ Penalties did not apply when individual production was equal to zero so that individual production could not be negative.
} 


\subsubsection{Internet Browsing}

At any point during the experiment, agents could switch from the work task to the leisure activity that consisted of browsing the Internet. Each activity was undertaken separately, in a different screen so that subjects could not sum tables while being on the Internet. Subjects were informed that their use of the Internet was strictly confidential. Subjects were free to consult their email or visit any web page. ${ }^{7}$ The Internet browser was embedded in the software so that the experimenter could keep record of the exact amount of time subjects spent on each activity. ${ }^{8}$

\subsubsection{Contracts}

At the beginning of each period, principals received an initial endowment of 200 cents. Then, principals proposed a linear contract $(\alpha, \beta)$ to the agent by offering a non-negative fixed pay, $\alpha \in[0,200]$, as well as a performance pay, $\beta \in[0,1]$, representing the share of the work output assigned to the agent. In line with the limited liability assumption in our theoretical framework, the principal could not "sell the firm" to the agent by proposing a negative fixed pay.

In addition to setting monetary incentives principals could set a goal to the agent (in the goal setting treatment). The goal was stated in terms of the production (in cents) of the agent. We informed participants that producing more or less than the goal neither generated rewards nor induced penalties to the agent. The principal could decide not to set a goal in which case the label "no goal" would appear on the screen.

After receiving the principal's offer (fixed pay, performance pay and production goal), the agent had to decide whether to accept it or to reject it. In case of acceptance, the agent would be rewarded according to the agreed-upon contract. The agent would then be able to work on the task or browse the Internet for leisure purposes. In case of rejection, the agent would only be able to browse the web for a fixed payment of $150 \propto$ and the principal would keep his or her initial endowment of $200 \notin$. The earnings for the agent and the principal are described in Table 1.

\footnotetext{
${ }^{7}$ Subjects were expected to follow the norms set by the university regarding the use of Internet on campus.

${ }^{8}$ The lab policy is to forbid cell phone use inside the lab. This ensures that embedded internet browsing is an accurate measure of on-the-job leisure.
} 
TABLE 1. Agents' and principals' earnings per period (in cents).

\begin{tabular}{c|c|c}
\hline \hline Agents' decision & Agents' earnings & Principals' earnings \\
\hline Offer accepted & $\alpha+\beta \times($ Agent production $)$ & $(200-\alpha)+(1-\beta) \times($ Agent production $)$ \\
Offer rejected & 150 & 200 \\
\hline
\end{tabular}

$(\alpha, \beta)$ represents the principal's offer, where $\alpha \in[0,200]$ and $\beta \in[0,1]$

\subsection{Treatments and Procedures}

We conducted two treatments (see Table 2). In the baseline treatment, principals offered a linear contract (fixed pay and performance pay) to the agent. In the goal setting treatment principals could set a wage-irrelevant goal to the agent in addition to monetary incentives.

TABLE 2. Summary of the treatments.

\begin{tabular}{|c|c|c|}
\hline Treatment & Description & $\begin{array}{l}\text { Number of participants } \\
\text { (observations) [sessions] }\end{array}$ \\
\hline Baseline & Principals propose a linear contract to the agent. & $54(162)[5]$ \\
\hline Goal Setting & $\begin{array}{l}\text { Principals propose a linear contract and a wage- } \\
\text { irrelevant goal to the agent. }\end{array}$ & $56(168)[5]$ \\
\hline
\end{tabular}

Our subject pool consisted of students from a major U.S. University. We recruited people who previously participated in related studies (Corgnet and Hernan-Gonzalez, 2015; Corgnet et al. 2015c) so as to ensure that they had experience in completing the work task used in this experiment. This was done so that subjects could accurately assess their skills on the task and better understand the consequences of each possible contract. We conducted a total of 10 sessions with ten or twelve subjects each for a total of 110 subjects (54 were assigned to the baseline and 56 were assigned to the goal setting treatment). ${ }^{9}$

The experiment was computerized and all of the interaction was anonymous. The instructions were displayed on subjects' computer screens (see Appendix B). Subjects had exactly 20 minutes to read the instructions. A 20-minute timer was shown on the laboratory screen. Three minutes before the end of the instructions period, a monitor announced the time remaining and handed out a printed copy of the summary of the instructions. None of the subjects asked for extra time to read the instructions. At the end of the 20-minute instruction round, the instructions file was closed, and the experiment started. The interaction between the experimenter and the subjects was negligible.

\footnotetext{
${ }^{9}$ Out of the ten sessions, five were conducted with ten people and five were conducted with twelve.
} 
At the end of the experiment and before payments were made, we elicited subjects social preferences (see online Appendix O.1) and asked them to report their math skills on a scale from 1 to 7 . These questionnaires lasted ten minutes.

Subjects were paid their earnings in cash at the end of the experiment. Individual earnings were computed as the sum of the earnings in the 6 periods. Subjects earned on average $\$ 31.6$ in addition to a $\$ 7$ show-up fee. Experimental sessions lasted on average two hours.

\subsection{Testable Conjectures}

The aim of our experiment is not to test the point predictions derived from the model introduced in Section 2. Instead, we aim at assessing the main implications of our theoretical framework regarding the relation between monetary incentives $(\alpha, \beta)$ and non-monetary incentives $(g)$. Based on our previous analysis, we state two conjectures that can be readily tested. Our first hypothesis states how goal setting affects the optimal labor contract.

\section{Hypothesis 1: Goal Setting and Labor Contracts [based on Corollary 1]}

We expect fixed pay to be greater and performance pay to be lower in the presence of goal setting than in its absence.

Note that Hypothesis 1 is a particular case of Corollary 1, which shows that higher goals increase fixed pay while decreasing performance pay. In our experiment we will consider two treatments: one in which goal setting is made available to the principal and one in which it is not (baseline). Therefore, we expect weaker monetary incentives with goal setting $\left(g^{*}>0\right)$ than in its absence $(g=0)$.

According to Corollary 2, the agency costs of inducing high effort are lower if the principal can combine monetary incentives with goal setting. Thus, we expect effort and production to be, on average, higher under goal setting than in the baseline. From Corollary 2 we also expect that the cost of inducing effort decreases with goal setting which will lead principals to earn significantly more in the presence of goal setting than in its absence. We thus derive the following hypothesis. 
Hypothesis 2: Production, Effort and Principals' Earnings [based on Corollary 2]

i) We expect production levels and work effort to be greater in the presence of goal setting than in its absence.

ii) We also expect principals' earnings to be greater in the presence of goal setting than in its absence.

\section{RESULTS}

We start the results section by comparing principals' offers across treatments. We then study contract acceptance, effort and production levels. In our analysis, we use linear and probit panel regressions with random effects and robust standard errors. ${ }^{10}$

\subsection{Contract Design (Hypothesis 1)}

Contracts are largely consistent with Hypothesis 1 according to which principals should offer weaker incentives when goal setting is present than when it is absent (see Table 3). For example, considering accepted offers, performance pay was lower in the presence of goal setting, $41.5 \%$, that in its absence, $45.1 \%$, while fixed pay was larger in the goal setting treatment, $104.9 \phi$, than in the baseline, 98.7 $\phi$. These differences are statistically significant as is shown in Table 3 where we report the p-value associated to the Goal Setting Dummy (which takes value 1 if a subject was involved in the goal setting treatment, and 0 otherwise) when conducting panel regressions using either fixed pay or performance pay as dependent variable. For the sake of completeness, we report the results of regressions using both accepted offers as well as all offers. However, it should be noted that considering all offers may not be an adequate test of our theoretical conjectures as rejected offers include null offers $(\alpha=\beta=0)$ that may bias the analysis. ${ }^{11}$

\footnotetext{
${ }^{10}$ Results are robust to using other specifications such as Tobit models, non-robust standard errors and wild cluster bootstrap standard errors (Cameron and Miller, 2011) as well as OLS regressions with clustered standard errors at the session level. These additional analyses are available upon request from the authors.

${ }^{11}$ If we remove extremely low offers from all principals' offers, the difference in performance pay across treatments becomes significant in that case as well. For example, if we remove all those offers for which fixed pay is zero cent and performance pay is $0 \%$ [less than $5 \%](\mathrm{n}=3)$ [n=8] the corresponding $p$-value becomes 0.092 [0.029].
} 
TABLE 3. Principals' offers across treatments.

\begin{tabular}{ccccc}
\hline \hline $\begin{array}{c}\text { Average } \\
\text { (Standard dev.) }\end{array}$ & Baseline & $\begin{array}{c}\text { Goal Setting } \\
\text { Treatment }\end{array}$ & $\begin{array}{c}\text { Goal Setting Dummy } \\
\text { P-value }^{\dagger}\end{array}$ \\
\hline \multirow{2}{*}{ Accepted offers } & Fixed pay & $\begin{array}{c}98.7 \phi \\
(28.7 \phi)\end{array}$ & $\begin{array}{c}104.9 \phi \\
(31.0 \phi)\end{array}$ & 0.077 \\
& Performance & $\begin{array}{c}45.1 \% \\
(13.3 \%)\end{array}$ & $\begin{array}{c}41.5 \% \\
(10.4 \%)\end{array}$ & 0.011 \\
& pay & {$[n=123]$} & {$[n=138]$} & \\
\hline All offers & Fixed pay & $\begin{array}{c}90.3 \phi \\
(34.9 \phi)\end{array}$ & $\begin{array}{c}100.3 \phi \\
(33.3 \phi)\end{array}$ & 0.003 \\
& Performance & $\begin{array}{c}42.5 \% \\
(16.9 \%)\end{array}$ & $\begin{array}{c}40.4 \% \\
(11.3 \%)\end{array}$ & 0.150 \\
& pay & {$[n=162]$} & {$[n=168]$} & \\
\hline
\end{tabular}

In this column we report the results of two linear panel regressions with robust standard errors with fixed pay and performance pay as dependent variables, and a Goal Setting Dummy (which takes value 1 if a subject was involved in the goal setting treatment and value 0 otherwise) as regressor. In particular, we report the $p$-value associated to the coefficient of the Goal Setting Dummy.

It is also worth noting that, in the great majority of the cases $(84.5 \%, 142 / 168)$, principals set a goal to the agent. ${ }^{12}$ Principals set an average goal of $306.7 \varnothing(\mathrm{SD}=118.2 \varnothing)$ (see Histogram $\mathrm{C} 1$ in Appendix C).

\subsection{Contract Acceptance}

The large majority of offers were accepted by agents in both the baseline $(75.9 \%, 123 / 162)$ and the goal setting treatment $(82.1 \%, 138 / 168)$. In our regression analysis (Table 4), we use as dependent variable a dummy (Accepted dummy) that takes value 1 if a given offer is accepted and takes value 0 otherwise. We use self-reported math skills as a control for subjects' ability. ${ }^{13}$ Not surprisingly, agents are more likely to accept the principal's offer when the fixed pay and the performance pay assigned to the agent are high. The treatment variable is never significant, except in the case in which we do not control for fixed pay ( $p$-value $=0.05)$. However, this

\footnotetext{
${ }^{12}$ If we consider as setting "no goals" instances in which production goals were set either at very low or at very high levels (such as the following five cases in: $2 \not, 2 \not, 3 \phi, 10,000 \phi$, and 1,000,000,000ф), then principals set goals in $81.6 \%$ of the cases.

${ }^{13}$ Our results are robust to introducing other measures of ability. For example, we can measure ability using a dummy variable which takes value 1 if a subject has completed his or her first table correctly and value 0 otherwise. Previous research has shown a positive and significant relationship between first table performance and ability on the task (Corgnet et al. 2015b). Considering a continuous measure such as the amount of time necessary to complete the first table correctly also gives similar results.
} 
significance may be reflecting treatment differences in fixed pay as the effect disappears when we control for only fixed pay or both, fixed pay and performance pay. ${ }^{14}$

TABLE 4. Probit panel regressions for contract acceptance (Accepted Dummy).

\begin{tabular}{|c|c|c|c|}
\hline Constant & $\begin{array}{c}0.90 * * \\
(0.39)\end{array}$ & $\begin{array}{l}-0.62 \\
(0.45)\end{array}$ & $\begin{array}{c}-3.68 * * * \\
(0.78)\end{array}$ \\
\hline Goal Setting Dummy & $\begin{array}{c}0.12 \\
(0.17)\end{array}$ & $\begin{array}{l}0.31 * \\
(0.16)\end{array}$ & $\begin{array}{c}0.14 \\
(0.19)\end{array}$ \\
\hline \multicolumn{4}{|l|}{ Contract offer } \\
\hline Fixed pay & $\begin{array}{c}0.02 * * * \\
(0.002)\end{array}$ & - & $\begin{array}{c}0.02 * * * \\
(0.004)\end{array}$ \\
\hline Performance pay & - & $\begin{array}{c}0.02 * * * \\
(0.01)\end{array}$ & $\begin{array}{c}0.04 * * * \\
(0.01)\end{array}$ \\
\hline Math skills & $\begin{array}{c}0.06 \\
(0.06)\end{array}$ & $\begin{array}{c}0.07 \\
(0.06)\end{array}$ & $\begin{array}{c}0.12 \\
(0.07)\end{array}$ \\
\hline Number of observations & 324 & 324 & 324 \\
\hline$\chi^{2}$ & $38.53 * * *$ & $22.23 * * *$ & 38.09 \\
\hline
\end{tabular}

\subsection{Effort and Production (Hypothesis 2i)}

In the goal setting treatment, agents produced on average $26.7 \%$ more than in the baseline despite receiving significantly lower performance pay (see Figure 2). The difference in production across treatments corresponds to a difference in subjects' hourly production of \$5.2. These results are consistent with Hypothesis $2 \mathrm{i}$.

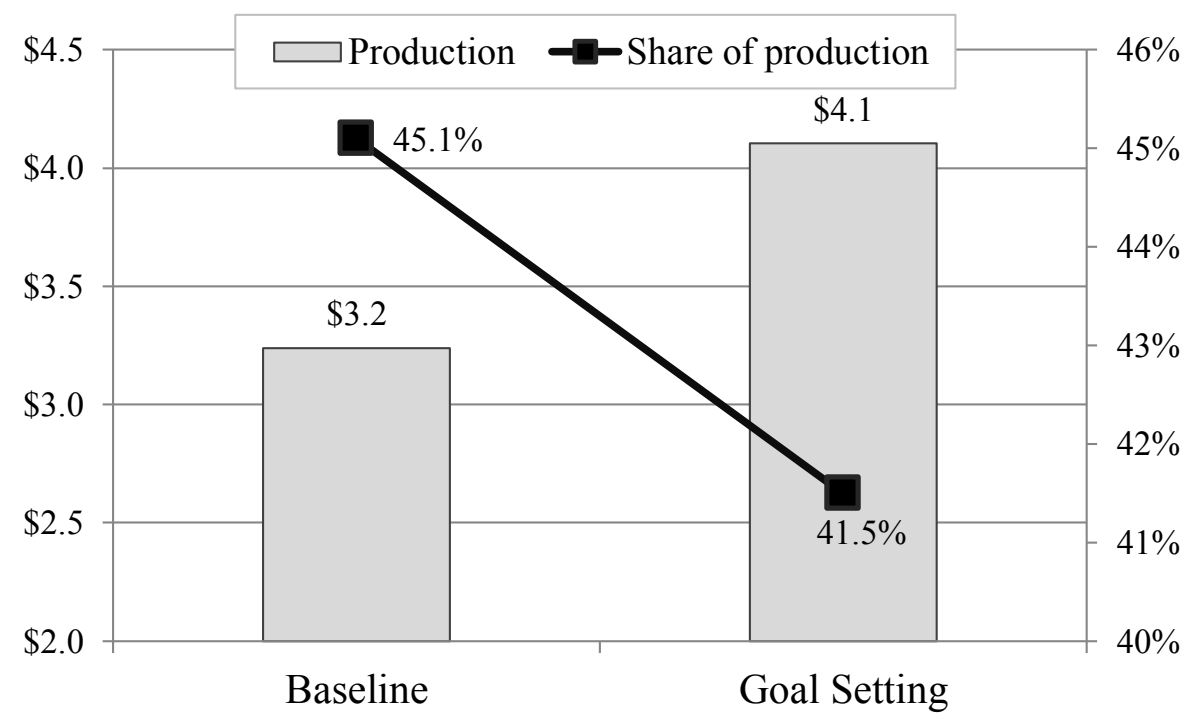

FIGURE 2.- Agents' average production (in US Dollars) and performance pay (for accepted offers) across treatments.

\footnotetext{
${ }^{14}$ The treatment variable is not significant $(p$-value $=0.11$ ) when we include neither fixed pay nor performance pay as controls.
} 
We confirm the statistical significance of these differences in Table 5. We find that the Goal Setting Dummy is significant whether controlling for fixed pay, performance pay or both. Fixed pay does not explain production levels in contrast with gift-exchange experiments in which the contract designed by the principal only includes fixed pay (e.g. Fehr et al. 1993). However, performance pay relates positively to agents' production, which stresses that, in line with our theoretical framework, monetary incentives continue to be relevant even in the presence of goal setting.

TABLE 5. Linear panel regressions for Production (in US Dollars).

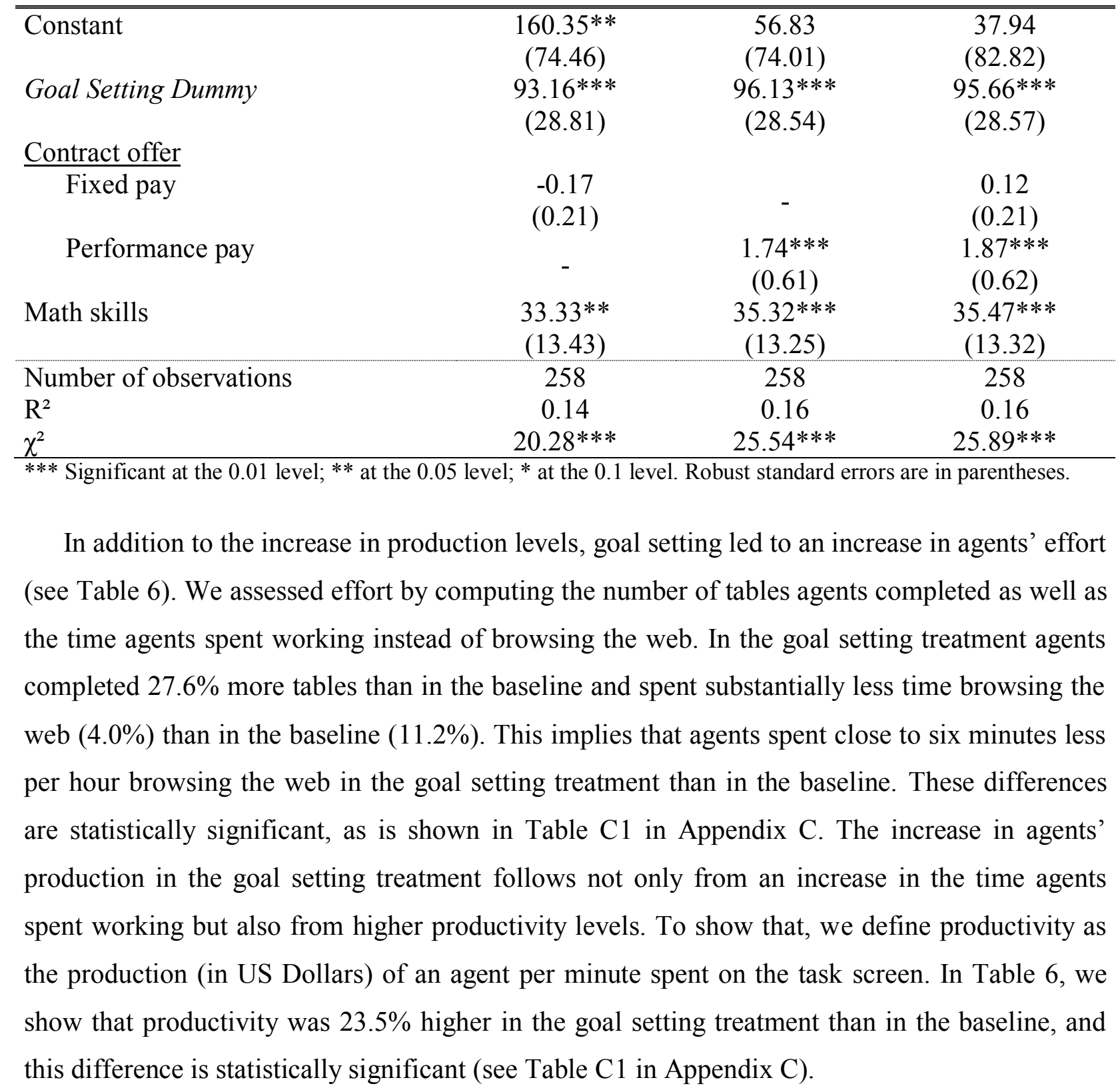


TABLE 6. Effort and productivity across treatments.

\begin{tabular}{lcc}
\hline $\begin{array}{c}\text { Average } \\
\text { (standard deviation) }\end{array}$ & Baseline & Goal Setting \\
\hline Internet use (\%) & $11.20 \%$ & $3.99 \%$ \\
& $(25.29 \%)$ & $(15.25 \%)$ \\
\hline \multirow{2}{*}{ Completed tables } & 9.76 & 12.45 \\
& $(4.80)$ & $(3.84)$ \\
Productivity & $\$ 0.34$ & $\$ 0.42$ \\
& $(\$ 0.16)$ & $(\$ 0.15)$ \\
\hline
\end{tabular}

In Table $\mathrm{C} 1$ in Appendix $\mathrm{C}$, we show that performance pay as well as math skills led agents to complete more tables and be more productive. However, performance pay and math skills did not affect the time agents spent on the work task. The presence of goal setting is the only variable that led agents to spend more time working and less time browsing. These findings seem to indicate that the use of goals may help agents perceive the task as more enjoyable leading them to reduce their leisure time on the job. This behavior is in line with our theoretical framework which assumes that setting goals to agents will generate non-monetary utility.

\subsection{Agency Costs and Principals' Earnings (Hypothesis 2ii)}

The higher level of production in the goal setting treatment than in the baseline led principals to earn significantly more under goal setting. The average hourly earnings for principals were $17.3 \%$ higher in the goal setting treatment, $\$ 19.7$, compared to the baseline, $\$ 16.8$ (see Table 7 ). This result confirms Hypothesis 2ii according to which principals can complement monetary incentives with non-monetary incentives to reduce agency costs.

Interestingly, agents' earnings were also higher in the goal setting treatment than in the baseline despite lower performance pay when goals were present (see last column in Table 7). This was the case because fixed pay as well as production were significantly higher in the goal setting treatment than in the baseline. 
TABLE 7. Linear panel regressions for earnings.

\begin{tabular}{|c|c|c|c|}
\hline & $\begin{array}{c}\text { Principal earnings } \\
\text { All offers } \\
\end{array}$ & $\begin{array}{c}\text { Principal earnings } \\
\text { Accepted offers }\end{array}$ & $\begin{array}{l}\text { Agent Earnings } \\
\text { Accepted offers }\end{array}$ \\
\hline Constant & $\begin{array}{c}258.30 * * * \\
(8.04)\end{array}$ & $\begin{array}{c}276.44 * * * \\
(9.85)\end{array}$ & $\begin{array}{c}23.48 \\
(39.47)\end{array}$ \\
\hline Goal Setting Dummy & $\begin{array}{c}51.29 * * * \\
(10.97)\end{array}$ & $\begin{array}{c}57.55 * * * \\
(12.72)\end{array}$ & $\begin{array}{c}42.51 * * * \\
(13.41)\end{array}$ \\
\hline Performance pay ${ }^{15}$ & - & - & $\begin{array}{c}3.28 * * * \\
(0.47)\end{array}$ \\
\hline Math skills & - & - & $\begin{array}{c}14.52 * * \\
(6.06)\end{array}$ \\
\hline Number of observations & 330 & 261 & 258 \\
\hline $\mathrm{R}^{2}$ & 0.06 & 0.07 & 0.25 \\
\hline$\chi^{2}$ & $21.87 * * *$ & $20.47 * * *$ & $57.45 * * *$ \\
\hline
\end{tabular}

An important implication of our findings is that weaker monetary incentives are not necessarily associated with lower monetary earnings for both agents and principals. Goal setting allows principals to boost work performance and profits while still paying more money to the agents.

\subsection{Robustness Checks}

In Appendix O.1, we show the robustness of all our findings when controlling for otherregarding preferences in addition to math skills. Social preferences have indeed been shown to be relevant in experimental tests of the principal-agent theory. In particular, subjects' decision to accept or reject a contract as well their decision to produce may be affected by other-regarding preferences (Keser and Willinger, 2000, 2007; Anderhub et al. 2002). Also, Cabrales et al. (2010) have shown that agents are more likely to select contract offers from principals who have social preferences which are similar to their own. ${ }^{16}$

In Appendix O.2, we turn to the analysis of the effect of individual goals in the goal setting treatment. Our objective is to check the soundness of our theoretical framework by showing that more challenging goals, whenever attainable, lead agents to increase their production. We also show that goal setting reduces the dispersion in production levels which tends to cluster around the goal. These findings are in line with standard goal setting models (e.g. Wu et al. 2008).

\footnotetext{
${ }^{15}$ We do not show the regression results that control for fixed pay as the coefficient associated to fixed pay is never statistically significant. This also helps avoid collinearity issues which could be induced by using both fixed pay and performance pay as controls in the regression. Our results continue to hold when controlling either for fixed pay or for both fixed pay and performance pay.

${ }^{16}$ This finding has important implications for organizational research potentially accounting for the observed heterogeneity in "corporate cultures" across firms.
} 


\section{CONCLUSIONS}

Using both agency models and experiments, we have shown that principals set weaker monetary incentives when they can set wage-irrelevant goals than when they cannot. This is the case because principals can reduce agency costs by substituting costly monetary incentives with non-monetary incentives. Despite weaker monetary incentives, agents work more in the presence of goal setting than in its absence generating higher earnings for principals.

Our findings contribute to the theory of incentives by showing that non-monetary incentives can remain effective even when monetary incentives are widely available. It follows that nonmonetary incentives are not second-best solutions that only gain popularity when monetary incentives are costly to implement. Our findings suggest that both monetary and non-monetary incentives effectively motivate people. This highlights the importance of studying different types of incentives jointly so as to provide effective guidance to practitioners.

Finally, our analysis constitutes a point of departure for a theory of the firm that uses nonmonetary incentives as a building block to explain why firms consistently rely on weak incentive schemes. To that end, one could extend our work by analyzing the interaction between monetary and non-monetary incentives in larger and more complex organizations involving, for example, multiple-layer hierarchies.

\section{REFERENCES}

Allen, E., P. Dechow, D. Pope, and G. Wu (2016): "Reference-Dependent Preferences: Evidence from Marathon Runners," Management Science, in press.

Anderhub, V., S. Gächter and M. Königstein (2002): "Efficient Contracting and Fair Play in a Simple Principal-Agent Experiment," Experimental Economics, 5(1), 5-27.

Baard, P. P., E. L. Deci and R. M. Ryan (2004): "Intrinsic Need Satisfaction: A Motivational Basis of Performance and Weil-Being in Two Work Settings," Journal of Applied Social Psychology, 34(10), 2045-2068.

Bartling, B., E. Fehr, M. Marechal, and D. Schunk (2009): "Egalitarianism and Competitiveness," American Economic Review, 99(2), 93-98.

Bénabou, R., and J. Tirole (2003): "Intrinsic and Extrinsic Motivation," Review of Economics Studies, 70, 489-520.

Bolton, P., and M. Dewatripont (2005): Contract Theory. MIT Press, Cambridge, MA. 
Cameron, A., and D. Miller. (2011): "Robust Inference with Clustered Data," Handbook of Empirical Economics and Finance, ed. by A. Ullah and D. E. A. Giles. Boca Raton, CRC Press, 1-28.

Cabrales, A., R. Miniaci, M. Piovesan and G. Ponti (2010): "Social Preferences and Strategic Uncertainty: An Experiment on Markets and Contracts," American Economic Review, 100, 2261-2278.

Charness, G. Masclet, D., and M.-C. Villeval (2014): "The Dark Side of Competition for Status," Management Science, 60(1), 38-55.

Chiappori P., and B. Salanié (2000): “Testing Contract Theory: A Survey of Some Recent Work," in: M. Dewatripont, L.P. Hansen, S. Turnovski, Advances in Economic Theory, Eighth World Congress of the Econometric Society, Cambridge University Press.

Corgnet, B., and R. Hernan-Gonzalez (2015): "Revisiting the Tradeoff between Risk and Incentives: The Shocking Effect of Random Shocks," Working Paper 15-05, Chapman University Economic Science Institute.

Corgnet, B., J. Gómez-Miñambres, and R. Hernan-Gonzalez, (2015a): "Goal Setting and Monetary Incentives: When Large Stakes Are Not Enough,” Management Science, 61(12), 2926-2944.

Corgnet, B., R. Hernan-Gonzalez, and S. Rassenti (2015b): "Firing Threats and Tenure: Incentive Effects and Impression Management," Games and Economic Behavior, 91, 97-113. Corgnet, B., R. Hernan-Gonzalez, and S. Rassenti (2015c): "Peer Pressure and Moral Hazard in Teams: Experimental Evidence," Review of Behavioral Economics, 2(4), 379-403.

Corgnet B., R. Hernan-Gonzalez, and E. Schniter. (2015d): "Why Real Leisure Really Matters: Incentive Effects on Real Effort in the Laboratory," Experimental Economics, 18(2), 284301.

Dalton, P., V. Gonzalez, and C. Noussair, (2015): "Paying with Self-Chosen Goals: Incentives and Gender Differences," CentER Discussion Paper Series No. 2015-021. Available at SSRN: http://ssrn.com/abstract=2583872 or http://dx.doi.org/10.2139/ssrn.2583872

De Meza, D., and D. Webb. (2007): "Incentive Design under Loss Aversion," Journal of the European Economic Association, 5(1), 66-92.

Deci, E. L. (1971): “Effects of Externally Mediated Rewards on Intrinsic Motivation,” Journal of Personality and Social Psychology, 18(1), 105-115.

Deci, E. L. (1975): “Intrinsic Motivation,” New-York: Plenum Press. 
Deci, E. L., and R. M. Ryan (1985): "Intrinsic Motivation and Self-determination in Human Behavior," New York: Plenum Press.

Deci, E. L., R. M. Ryan, M. Gagné, D. R. Leone, J. Usunov, and B, P. Kornazheva (2001): "Need Stisfaction, Motivation, and Well-Being in the Work Organizations of a Former Eastern Bloc Country: A Cross-Cultural Study of Self-Determination," Personality and Social Psychology Bulletin, 27, 930-942.

Dickinson, D., and M. C. Villeval (2008): "Does Monitoring Decrease Work Effort? The Complementarity between Agency and Crowding-Out Theories," Games and Economic Behavior, 63(1), 56-76.

Dittmann, I., E. Maug and O. Spalt (2010): "Sticks or Carrots? Optimal CEO Compensation when Managers are Loss Averse,” The Journal of Finance, 65(6), 2015-2050.

Dohmen, T., and A. Falk (2011): "Performance Pay and Multi-Dimensional Sorting: Productivity, Preferences and Gender," American Economic Review, 101(2), 556-590.

Eriksson, T., A. Poulsen, and M. C. Villeval (2009): "Feedback and Incentives: Experimental Evidence," Labour Economics, 16 (6), 679-688.

Falk, A. and M. Kosfeld (2006): “The Hidden Costs of Control," American Economic Review, 96, 1611-1630.

Fehr, E., H. Herz, and T. Wilkening (2013): “The Lure of Authority: Motivation and Incentive Effects of Power," American Economic Review, 103(4), 1325-1359.

Fehr, E., G. Kirchsteiger, and A. Riedl (1993): "Does Fairness Prevent Market Clearing? An Experimental Investigation," Quarterly Journal of Economics, 108 (2), 437-460.

Frey, B. S., and R. Jegen, (2001): "Motivation Crowding Theory," Journal of Economic Surveys, 15(5), 589-611.

Gneezy, U., S. Meier, and P. Rey-Biel (2011): “When and Why Incentives (Don’t) Work to Modify Behavior," Journal of Economic Perspectives, 25(4), 191-210.

Goerg, S. J., and S. Kube (2012): “Goals (th)at Work- Goals, Monetary Incentives, and Workers' Performance," Working Paper Series of the Max Planck Institute for Research on Collective Goods Bonn, 2012/19.

Gómez-Miñambres, J. (2012): "Motivation through Goal Setting," Journal of Economic Psychology, 33(6), 1223-1239. 
Heath, C., R. Larrick, and G. Wu (1999): “Goals as Reference Points,” Cognitive Psychology, 38, 79-109.

Herweg, F., D. Muller and P. Weinschenk (2010): “Binary Payment Schemes: Moral Hazard and Loss Aversion," American Economic Review, 100(5), 2451-2477.

Holmström, B. (1979): “Moral Hazard and Observability,” Bell Journal of Economics, 10(1), 7491.

Kahneman, D., and A. Tversky (1979): "Prospect Theory: An Analysis of Decisions Under Risk," Econometrica, 47 (2), 313-327.

Kamenica, E. (2012): “Behavioral Economics and Psychology of Incentives," Annual Review of Economics, 4, 427-452.

Keser, C., and M. Willinger (2000): "Principals' Principles When Agents' Actions are Hidden," International Journal of Industrial Organization, 18(1), 163-185.

Keser, C., and M. Willinger (2007): “Theories of Behavior in Principal-agent Relationships With Hidden Action," European Economic Review, 51(6), 1514-1533.

Kosfeld, M., and S. Neckermann (2011): “Getting More Work for Nothing? Symbolic Awards and Worker Performance," American Economic Journal: Microeconomics, 3, 86-99.

Kőszegi, B., and M. Rabin (2006): “A Model of Reference-Dependent Preferences,” Quarterly Journal of Economics, 121(4), 1133-1166.

Laffont, J. J., and D. Martimort (2002): “The Theory of Incentives: The Principal-agent Model," Princeton University Press: Princeton, N.J.; Oxford.

van Lent, M. and M. Souverijny (2015): "Goal Setting and Raising the Bar: A Field Experiment," Working Paper, Erasmus University.

Locke, E. A. (1996): "Motivation through Conscious Goal Setting," Applied \& Preventive Psychology, 5, 117-124.

Locke, E. A., and G. P. Latham (2002): "Building a Practically Useful Theory of Goal Setting and Task Motivation," American Psychologist, 57, 705-717.

Niederle, M., and L. Vesterlund (2007): “Do Women Shy Away from Competition? Do Men Compete Too Much?” The Quarterly Journal of Economics, 3(8), 1067-1101.

Ryan, R. M., and E. L. Deci (2000): "Self-determination Theory and the Facilitation of Intrinsic Motivation, Social Development, and Well-Being," American Psychologist, 55, 68-78.

Wu, G., C. Heath, and R. Larrick (2008): “A Prospect Theory Model of Goal Behavior,” mimeo University of Chicago. 


\section{APPENDIX A: Theoretical Framework}

The principal's problem is to maximize profits subject to participation and incentives compatibility constrains of each agent type. For the sake of illustration, we assume that $\Delta y:=$ $y_{H}-y_{L}=y_{L}>0$. This assumption greatly simplifies the analysis but is not key for our results.

If both types of agents, $l$ and $h$, exert a positive effort, the expected production is given by $\mathrm{E}(y)=\theta\left(\pi_{1} y_{\mathrm{H}}+\left(1-\pi_{1}\right) y_{\mathrm{L}}\right)+(1-\theta) \pi_{1} y_{\mathrm{L}}=\Delta y\left(\theta+\pi_{1}\right)$ and the expected compensation is given by $\mathrm{E}(\mathrm{w})=\theta\left(\pi_{1} \mathrm{w}_{\mathrm{H}}+\left(1-\pi_{1}\right) \mathrm{w}_{\mathrm{L}}\right)+(1-\theta)\left(\pi_{1} \mathrm{w}_{\mathrm{L}}+\left(1-\pi_{1}\right) \alpha\right)=\beta E(y)+\alpha$ where $\mathrm{w}_{H}=\alpha+\beta y_{H}$ and $\mathrm{w}_{L}=\alpha+\beta y_{L}$. Principal's profits are given by $E(y)-E(\mathrm{w})=$ $(1-\beta) E(y)-\alpha$.

The high-ability agent's incentive compatibility constraint $\left(\mathrm{IC}_{\mathrm{h}}\right)$ is given by:

$$
\begin{aligned}
\pi_{1}\left[\mathrm{w}_{\mathrm{H}}+v\left(y_{\mathrm{H}}-g\right)\right]+\left(1-\pi_{1}\right)\left[\mathrm{w}_{\mathrm{L}}+v\left(y_{\mathrm{L}}-g\right)\right]-c \\
\quad \geq \pi_{0}\left[\mathrm{w}_{\mathrm{H}}+v\left(y_{\mathrm{H}}-g\right)\right]+\left(1-\pi_{0}\right)\left[\mathrm{w}_{\mathrm{L}}+v\left(y_{\mathrm{L}}-g\right)\right]
\end{aligned}
$$

and the low ability agent's incentive compatibility constraint $\left(\mathrm{IC}_{1}\right)$ is given by:

$$
\begin{aligned}
& \pi_{1}\left[\mathrm{w}_{\mathrm{L}}+v\left(\mathrm{y}_{\mathrm{L}}-g\right)\right]+\left(1-\pi_{1}\right)[\alpha+v(-g)]-c \\
& \quad \geq \pi_{0}\left[\mathrm{w}_{\mathrm{L}}+v\left(y_{\mathrm{L}}-g\right)\right]+\left(1-\pi_{0}\right)[\alpha+v(-g)]
\end{aligned}
$$

Thus, if $\left(\mathrm{IC}_{\mathrm{i}}\right)$ is satisfied, agent $i \in\{l, h\}$ prefers to exert a positive effort.

By normalizing to zero the agent's reservation utility we can define the high-ability agent's participation constraint $\left(\mathrm{PC}_{\mathrm{h}}\right)$ as:

$\pi_{1}\left[\mathrm{w}_{\mathrm{H}}+v\left(y_{\mathrm{H}}-g\right)\right]+\left(1-\pi_{1}\right)\left[\mathrm{w}_{\mathrm{L}}+v\left(y_{\mathrm{L}}-g\right)\right]-c \geq 0$

and the low-ability agent's participation constraint $\left(\mathrm{PC}_{1}\right)$ as:

$\pi_{1}\left[\mathrm{w}_{\mathrm{L}}+v\left(\mathrm{y}_{\mathrm{L}}-g\right)\right]+\left(1-\pi_{1}\right)[\alpha+v(-g)]-c \geq 0$

If $\left(\mathrm{PC}_{\mathrm{i}}\right)$ is satisfied, agent $i$ is willing to sign the contract with the principal.

Rearranging terms we can rewrite the incentive compatibility and participation constraints as:

$\Delta \pi\left[\beta\left(y_{H}-y_{L}\right)+\Delta v_{H L, g}\right] \geq c$ 
$\Delta \pi\left[\beta y_{L}+\Delta v_{L 0, g}\right] \geq c$

$\alpha+\pi_{1}\left[\beta y_{H}+v_{H, g}\right]+\left(1-\pi_{1}\right)\left[\beta y_{L}+v_{L, g}\right] \geq c$

$\alpha+\pi_{1}\left[\beta y_{L}+v_{L, g}\right]+\left(1-\pi_{1}\right) v_{0, g} \geq c$

A feasible contract is a pair of wages and a goal $\{\alpha, \beta, \mathrm{g}\}$ that induce positive effort ensuring agent's participation. The optimal contract is the solution of the following problem:

$$
\begin{gathered}
\max _{\{\alpha, \beta, g\}}(1-\beta) E(y)-\alpha \\
\text { subject to }\left(\mathrm{IC}_{\mathrm{h}}, \mathrm{IC}_{\mathrm{l}}, \mathrm{PC}_{\mathrm{h}}, \mathrm{PC}_{\mathrm{l}}\right)
\end{gathered}
$$

\section{Proof of Proposition 1}

The principal problem (P1) consists in motivating agent's effort at the lowest monetary cost using a linear contract and a wage-irrelevant goal.

Since $\mathrm{PC}_{\mathrm{L}}$ implies $\mathrm{PC}_{\mathrm{H}}$ in equilibrium:

$$
\alpha_{g}=\max \left\{c-\pi_{1}\left[\beta_{g} \Delta y+v_{L, g}\right]-\left(1-\pi_{1}\right) v_{0, g}, 0\right\} .
$$

Depending on model parameters we have:

$$
\begin{aligned}
& \text { a. } \Delta v_{H L, g}>\Delta v_{L 0, g} \text { so } \mathrm{IC}_{1} \text { implies } \mathrm{IC}_{\mathrm{h}} . \\
& \text { b. } \Delta v_{H L, g} \leq \Delta v_{L 0, g} \text { so } \mathrm{IC}_{\mathrm{h}} \text { implies } \mathrm{IC}_{\mathrm{l}} .
\end{aligned}
$$

Therefore, in case (a) we have that:

$\beta_{g}^{*}=\max \left\{\frac{1}{\Delta y}\left[\frac{c}{\Delta \pi}-\Delta v_{L 0, g}\right], 0\right\}$

and by plugging (A2) in (A1) we get:

$\alpha_{g}^{*}=\max \left\{-\frac{c \pi_{0}}{\Delta \pi}-v_{0, g}, 0\right\}$,

Note that for any $\alpha_{g}>0, \frac{d \alpha_{g}}{d g}>0$. Moreover, by the properties of $v(\cdot)$ we know that $\frac{d^{2} v(y-g)}{d g d y}>$ 0 iff $y>g$ and $\frac{d^{2} v(y-g)}{d g d y}<0$ iff $y<g$. Therefore, $\frac{d \Delta v_{L 0, g}}{d g}<0$ and hence $\frac{d \beta_{g}}{d g}>0$ for any $\beta_{g}>0$. 
This implies that case (a) cannot arise in equilibrium with positive goals, because the principal could decrease both $\alpha_{g}$ and $\beta_{g}$ by setting a lower goal.

Therefore, only case (b) can emerge in equilibrium. In this case,

$\beta_{g}^{*}=\max \left\{\frac{1}{\Delta y}\left[\frac{c}{\Delta \pi}-\Delta v_{H L, g}\right], 0\right\}$

Moreover, by plugging (A4) in (A1) we get:

$\alpha_{g}^{*}=\max \left\{-c \frac{\pi_{0}}{\Delta \pi}-\pi_{1}\left(\Delta v_{L 0, g}-\Delta v_{H L, g}\right)-v_{0 g}, 0\right\}$

Finally, the principal will set the goal that maximizes profits. Thus, the optimal goal is given by

$$
g^{*}=\operatorname{argmax}_{g}\left(1-\beta_{g}^{*}\right) E(y)-\alpha_{g}^{*}=\operatorname{argmin}_{g} \alpha_{g}^{*}+\beta_{g}^{*} E(y)
$$

It remains to be proved that $g^{*} \in\left(0, y_{H}\right)$

We first prove that $g^{*}>0$. Let's assume by contradiction that $g^{*}=0$. In this case,

$$
\beta_{0}^{*}=\max \left\{\frac{1}{\Delta y}\left[\frac{c}{\Delta \pi}-\Delta v_{H L, 0}\right], 0\right\}
$$

And $\alpha_{0}^{*}=\max \left\{-c \frac{\pi_{0}}{\Delta \pi}-\pi_{1}\left(\Delta v_{L 0, g}-\Delta v_{H L, g}\right), 0\right\}=0$

Let's consider a goal $\underline{g}=\varepsilon$, where $\varepsilon>0$ is sufficiently small so that $\alpha_{\varepsilon}=0$. In this case,

$$
\beta_{\varepsilon}^{*}=\max \left\{\frac{1}{\Delta y}\left[\frac{c}{\Delta \pi}-\Delta v_{H L, \varepsilon}\right], 0\right\}
$$

Since, by property (v) of $v(\cdot)$ we know that $\Delta v_{H L, 0}<\Delta v_{H L, \varepsilon}$, this implies that for any positive performance pay, $\beta_{\varepsilon}^{*}<\beta_{0}^{*}$, and hence $g$ yields greater profits than $g^{*}=0$.

To prove that $g^{*}<y_{H}$ note that if $g \geq y_{H}$ then $\Delta v_{H L, g}<\Delta v_{L 0, g}$ and as we proved above (case a) the principal would be better off setting a lower goal.

\section{Proof of Corollary 1}

By property (iii) of $v(\cdot)$ we know that $v_{0 g}=-\lambda v(g)$. Therefore, we can rewrite equation (A5) as

$$
\alpha_{g}^{*}=\max \left\{-c \frac{\pi_{0}}{\Delta \pi}-\pi_{1}\left(\Delta v_{L 0, g}-\Delta v_{H L, g}\right)+\lambda v(g), 0\right\}
$$


Therefore, $\alpha_{g}^{*}>0$ iff $\lambda>\frac{-c \frac{\pi_{0}}{\Delta \pi}-\pi_{1}\left(\Delta v_{L 0, g}-\Delta v_{H L, g}\right)}{v(g)}>0$. Note also that given that $g^{*}>0$ there is always a sufficiently high $\lambda$ so that $\alpha_{g^{*}}^{*}>0$.

If $\alpha_{g}^{*}>0$, the optimal goal is the solution of the problem (P2). The first order condition of this problem is:

$-\frac{d \beta_{g}^{*}}{d g} E(y)-\frac{d \alpha_{g}^{*}}{d g}=0$

Therefore, $\frac{d \beta_{g}^{*}}{d g}$ and $\frac{d \alpha_{g}^{*}}{d g}$ must have opposite signs.

Deriving both sides of equation (A1) with respect to g, we get that:

$-\frac{d \alpha_{g}^{*}}{d g}=-\pi_{1}\left[\frac{d \beta_{g}^{*}}{d g} y_{L}+\frac{d v_{L, g}}{d g}\right]-\left(1-\pi_{1}\right) \frac{d v_{0, g}}{d g}$

Thus, by plugging equation (A7) in equation (A6) we get:

$\frac{d \beta_{g}^{*}}{d g}=\frac{\pi_{1} \frac{d v_{L, g}}{d g}+\left(1-\pi_{1}\right) \frac{d v_{0, g}}{d g}}{E[y]-\pi_{1} y_{L}}$

Note that since $\frac{d v_{L, g}}{d g}$ and $\frac{d v_{0, g}}{d g}$ are both negative (see properties of function $v(\cdot)$ in the main text), the numerator of this expression is negative. Moreover, since $\mathrm{E}(\mathrm{y})=\theta\left(\pi_{1} y_{\mathrm{H}}+\left(1-\pi_{1}\right) y_{\mathrm{L}}\right)+$ $(1-\theta) \pi_{1} \mathrm{y}_{\mathrm{L}}$, the denominator is positive for any $\theta>0$. Therefore, $\frac{d \beta_{g}^{*}}{d g}<0$ and by equation (A6), $\frac{d \alpha_{g}^{*}}{d g}>0$.

Finally, it is possible that $\alpha_{g}^{*}=0$, if $\lambda \leq \frac{-c \frac{\pi_{0}}{\Delta \pi}-\pi_{1}\left(\Delta v_{L 0, g}-\Delta v_{H L, g}\right)}{v(g)}$, and/or $\beta_{g}^{*}=0$, if $\Delta \mathrm{v}_{H L, g}>\frac{c}{\Delta \pi}$, so the result follows.

\section{Proof of Corollary 2}

It follows directly from Proposition 1. 
APPENDIX B: Instructions

\author{
Click here
}

Link: https://goo.gl/Smg9M8 


\section{APPENDIX C}

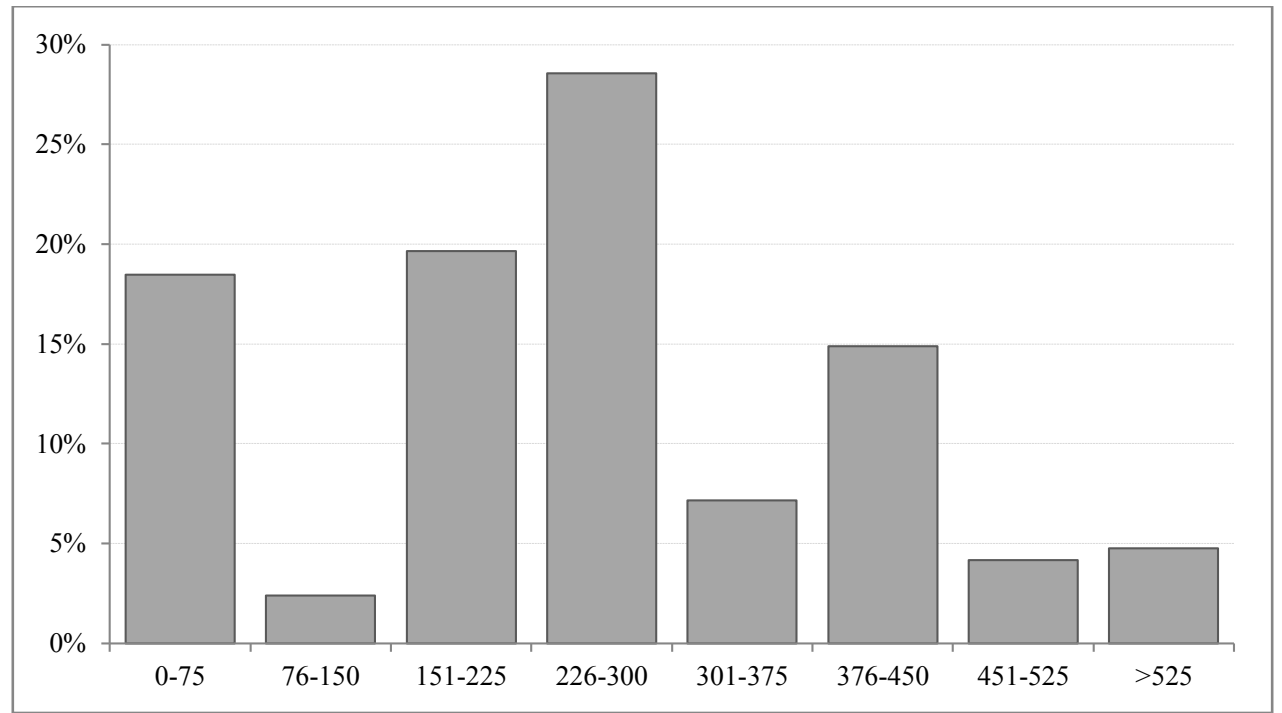

FIGURE C1.- Histogram of goals set by principals (in cents).

TABLE C1. Linear panel regressions for effort and productivity.

\begin{tabular}{lccc}
\hline \hline & Internet use (\%) & Tables completed & Productivity \\
\hline Constant & $13.59^{*}$ & $3.75^{* *}$ & 0.08 \\
Goal Setting Dummy & $(7.41)$ & $(1.76)$ & $(0.07)$ \\
& $-9.37 * *$ & $3.18^{* * *}$ & $0.08^{* * *}$ \\
Performance pay & $(4.06)$ & $(0.76)$ & $(0.03)$ \\
& -0.09 & $0.04 * * *$ & $0.001^{* * *}$ \\
Math skills & $(0.09)$ & $(0.02)$ & $(0.001)$ \\
& 0.78 & $0.72 * *$ & $0.04 * * *$ \\
Number of observations & $(1.28)$ & $(0.31)$ & $(0.01)$ \\
$\mathrm{R}^{2}$ & 258 & 258 & 254 \\
$\chi^{2}$ & 0.04 & 0.16 & 0.18 \\
\hline$* * *$ Significant at the 0.01 level; ** at the 0.05 level; * at the 0.1 level. Robust standard errors are in parentheses.
\end{tabular}




\section{APPENDIX O.1 (For Online Publication)}

\section{Social preferences}

We elicited social preferences à la Bartling et al. (2009) by asking subjects to make four choices between two possible allocations of money between themselves and another anonymous subject with whom they were randomly matched. The allocation decisions are described in Table O1. Option A always yielded an even distribution of money ( $\$ 2$ to the self and the other subject). Option B yielded uneven payoffs: $(\$ 2, \$ 1),(3 \$, \$ 1),(2 \$, \$ 4)$, and $(3 \$, \$ 5)$ in Games 1, 2, 3 and 4, respectively. We classify subjects following Bartling et al. (2009) into four social preferences categories as is described in the last column of the table. Prosocial types prefer equal distributions of income even when they have the possibility to earn more than the other subjects, as is the case in Game 2. Envy types dislike earning less than the other subject and choose Option A in the last two games even if it implies a lower payoff to themselves (Game 4).

Following the authors, we finally characterize subjects as either ahead (behind) averse if they were both prosocial and costly prosocial (envious and costly envious). Egalitarian subjects are defined as being both ahead and behind averse.

TABLE O1. Social preferences elicitation (Bartling et al. 2009).

\begin{tabular}{|c|c|c|c|}
\hline Game & $\begin{array}{c}\text { Option A } \\
\text { Payoff self, Payoff other }\end{array}$ & $\begin{array}{c}\text { Option B } \\
\text { Payoff self, Payoff } \\
\text { other }\end{array}$ & $\begin{array}{c}\text { Social preferences } \\
\text { type if choice is } \\
\underline{\text { Option A }}\end{array}$ \\
\hline 1 & $\$ 2, \$ 2$ & $\$ 2, \$ 1$ & Prosociality \\
\hline 2 & $\$ 2, \$ 2$ & $\$ 3, \$ 1$ & Costly Prosociality \\
\hline 3 & $\$ 2, \$ 2$ & $\$ 2, \$ 4$ & Envy \\
\hline 4 & $\$ 2, \$ 2$ & $\$ 3, \$ 5$ & Costly Envy \\
\hline
\end{tabular}

In Tables D1, D2, D3 and D4 we replicate the results reported in Tables 4, 5, C1 and 7, respectively, controlling for subjects' social preferences. 
TABLE O2. Probit panel regressions for the Accepted Dummy controlling for social preferences.

\begin{tabular}{|c|c|c|c|}
\hline Constant & $\begin{array}{c}-0.89 * * \\
(0.40)\end{array}$ & $\begin{array}{l}-0.75 \\
(0.47)\end{array}$ & $\begin{array}{c}-3.67 * * * \\
(0.76)\end{array}$ \\
\hline Goal Setting Dummy & $\begin{array}{c}0.08 \\
(0.19)\end{array}$ & $\begin{array}{l}0.35 * * \\
(0.16)\end{array}$ & $\begin{array}{c}0.13 \\
(0.19)\end{array}$ \\
\hline \multicolumn{4}{|l|}{ Contract offer } \\
\hline Fixed pay & $\begin{array}{l}0.02 * * * \\
(0.003)\end{array}$ & - & $\begin{array}{c}0.02 * * * \\
(0.01)\end{array}$ \\
\hline Performance pay & - & $\begin{array}{c}0.03 * * * \\
(0.01)\end{array}$ & $\begin{array}{c}0.04 * * * \\
(0.01)\end{array}$ \\
\hline Math skills & $\begin{array}{c}0.06 \\
(0.06)\end{array}$ & $\begin{array}{c}0.06 \\
(0.06)\end{array}$ & $\begin{array}{c}0.11 \\
(0.07)\end{array}$ \\
\hline \multicolumn{4}{|l|}{ Social preferences } \\
\hline Ahead averse & $\begin{array}{c}0.47 \\
(0.29)\end{array}$ & $\begin{array}{c}0.30 \\
(0.36)\end{array}$ & $\begin{array}{c}0.43 \\
(0.27)\end{array}$ \\
\hline Behind averse & $\begin{array}{l}-0.03 \\
(0.19)\end{array}$ & $\begin{array}{c}0.21 \\
(0.16)\end{array}$ & $\begin{array}{c}0.05 \\
(0.19)\end{array}$ \\
\hline $\begin{array}{l}\text { Number of observations } \\
\chi^{2}\end{array}$ & $\begin{array}{c}324 \\
38.98 * * *\end{array}$ & $\begin{array}{c}324 \\
23.68^{* * *}\end{array}$ & $\begin{array}{c}324 \\
38.36^{* * * *}\end{array}$ \\
\hline
\end{tabular}

TABLE O3. Linear panel regressions for Production (in US Dollars) controlling for social preferences.

\begin{tabular}{|c|c|c|c|}
\hline Constant & $\begin{array}{c}149.40 * * \\
(73.14)\end{array}$ & $\begin{array}{c}43.96 \\
(73.26)\end{array}$ & $\begin{array}{c}25.70 \\
(82.88)\end{array}$ \\
\hline Goal Setting Dummy & $\begin{array}{c}97.99 * * * \\
(30.71)\end{array}$ & $\begin{array}{c}101.43 * * * \\
(30.47)\end{array}$ & $\begin{array}{c}100.92 * * * \\
(30.52)\end{array}$ \\
\hline \multicolumn{4}{|l|}{ Contract offer } \\
\hline Fixed pay & $\begin{array}{l}-0.18 \\
(0.22)\end{array}$ & - & $\begin{array}{c}0.12 \\
(0.21)\end{array}$ \\
\hline Performance pay & - & $\begin{array}{c}1.74 * * * \\
(0.62)\end{array}$ & $\begin{array}{c}1.87 * * * \\
(0.62)\end{array}$ \\
\hline Math skills & $\begin{array}{c}32.96 * * \\
(14.05)\end{array}$ & $\begin{array}{c}35.00 * * \\
(13.82)\end{array}$ & $\begin{array}{l}35.20 * * \\
(13.91)\end{array}$ \\
\hline \multicolumn{4}{|l|}{ Social preferences } \\
\hline Ahead averse & $\begin{array}{c}-1.57 \\
(42.71)\end{array}$ & $\begin{array}{c}-4.36 \\
(42.77)\end{array}$ & $\begin{array}{c}-5.76 \\
(43.72)\end{array}$ \\
\hline Behind averse & $\begin{array}{c}17.60 \\
(32.43)\end{array}$ & $\begin{array}{c}19.08 \\
(32.12)\end{array}$ & $\begin{array}{c}18.68 \\
(32.15)\end{array}$ \\
\hline Number of observations & 258 & 258 & 258 \\
\hline$\chi^{2}$ & $21.86 * * *$ & $26.53 * * *$ & $26.67 * * *$ \\
\hline
\end{tabular}


TABLE O4. Linear panel regressions for effort and productivity controlling for social preferences.

\begin{tabular}{|c|c|c|c|}
\hline & Internet use $(\%)$ & Tables completed & Productivity \\
\hline Constant & $\begin{array}{l}15.01 * \\
(8.37)\end{array}$ & $\begin{array}{l}3.32 * \\
(1.80)\end{array}$ & $\begin{array}{c}0.06 \\
(0.07)\end{array}$ \\
\hline Goal Setting Dummy & $\begin{array}{c}-9.99 * * \\
(4.68)\end{array}$ & $\begin{array}{c}3.36 * * * \\
(0.83)\end{array}$ & $\begin{array}{c}0.09 * * * \\
(0.03)\end{array}$ \\
\hline \multicolumn{4}{|l|}{ Contract offer } \\
\hline Performance pay & $\begin{array}{l}-0.09 \\
(0.09)\end{array}$ & $\begin{array}{c}0.04 * * * \\
(0.02)\end{array}$ & $\begin{array}{c}0.002 * * * \\
(0.001)\end{array}$ \\
\hline Math skills & $\begin{array}{c}1.09 \\
(1.34)\end{array}$ & $\begin{array}{c}0.72 * * \\
(0.33)\end{array}$ & $\begin{array}{c}0.04 * * * \\
(0.01)\end{array}$ \\
\hline \multicolumn{4}{|l|}{ Social preferences } \\
\hline Ahead averse & $\begin{array}{c}-8.92 * * * \\
(2.94)\end{array}$ & $\begin{array}{l}-0.50 \\
(0.96)\end{array}$ & $\begin{array}{l}-0.02 \\
(0.04)\end{array}$ \\
\hline Behind averse & $\begin{array}{l}-3.46 \\
(4.77)\end{array}$ & $\begin{array}{c}0.59 \\
(0.87)\end{array}$ & $\begin{array}{c}0.02 \\
(0.03)\end{array}$ \\
\hline Number of observations & 258 & 258 & 254 \\
\hline $\mathrm{R}^{2}$ & 0.05 & 0.16 & 0.18 \\
\hline$\chi^{2}$ & $13.30 * *$ & $29.29 * * *$ & $29.58 * * *$ \\
\hline
\end{tabular}

TABLE O5. Linear panel regressions for earnings controlling for social preferences.

\begin{tabular}{|c|c|c|c|}
\hline & $\begin{array}{c}\text { Principal earnings } \\
\text { All offers }\end{array}$ & $\begin{array}{c}\text { Principal earnings } \\
\text { Accepted offers }\end{array}$ & $\begin{array}{l}\text { Agent Earnings } \\
\text { Accepted offers }\end{array}$ \\
\hline Constant & $\begin{array}{c}255.44 * * * \\
(12.31)\end{array}$ & $\begin{array}{c}270.50 * * * \\
(15.09)\end{array}$ & $\begin{array}{c}15.02 \\
(39.18)\end{array}$ \\
\hline Goal Setting Dummy & $\begin{array}{c}52.57 * * * \\
(11.41)\end{array}$ & $\begin{array}{c}59.03 * * * \\
(13.62)\end{array}$ & $\begin{array}{c}45.98 * * * \\
(14.07)\end{array}$ \\
\hline \multicolumn{4}{|l|}{ Contract offer } \\
\hline Performance pay & - & - & $\begin{array}{c}3.29 * * * \\
(0.47)\end{array}$ \\
\hline \multicolumn{4}{|l|}{ Ability measures } \\
\hline Self-reported skills & - & - & $\begin{array}{c}14.03 * * \\
(6.26)\end{array}$ \\
\hline \multicolumn{4}{|l|}{ Social preferences } \\
\hline Ahead averse & $\begin{array}{l}-12.98 \\
(20.32)\end{array}$ & $\begin{array}{c}8.08 \\
(23.75)\end{array}$ & $\begin{array}{c}7.61 \\
(17.23)\end{array}$ \\
\hline Behind averse & $\begin{array}{c}4.87 \\
(11.88)\end{array}$ & $\begin{array}{c}8.08 \\
(13.86)\end{array}$ & $\begin{array}{c}13.65 \\
(14.93)\end{array}$ \\
\hline Number of observations & 330 & 261 & 258 \\
\hline $\mathrm{R}^{2}$ & 0.06 & 0.07 & 0.26 \\
\hline - & $21.87 * * *$ & $20.58 * * *$ & $61.38 * * *$ \\
\hline
\end{tabular}




\section{APPENDIX O.2 (For Online Publication) On the internal mechanics of the goal setting model}

\section{O.2.1. On the positive effect of challenging but attainable goals}

After assessing the aggregate effect of goals in previous sections, we turn to the analysis of the effect of individual goals in the goal setting treatment. Our objective is to deepen our understanding of the effect of goals and connect our findings to our theoretical framework. This section thus tests the internal mechanics of our model instead of its main conjectures. To understand the effect of individual goals, we need to identify those goals which were reasonably accurate in the sense of being attainable by agents of a given ability level. To that end, we start by building a measure of ability on the task to predict the production level a given participant should be able to complete correctly in the work task. We denote this predictor of performance by work task ability. This variable is constructed for each participant $i$ as follows:

$$
\begin{aligned}
& \text { Work task ability }=\widehat{\alpha}_{0}+\widehat{\alpha}_{1} \times(\text { Self-reported }) \text { Math skills } \\
& +\widehat{\alpha}_{2} \times \text { First table correct }_{i}+\widehat{\alpha}_{3} \text { First correct table time } \\
& i
\end{aligned}
$$

where First table correct $t_{i}$ is a dummy variable that takes value 1 if subject $i$ completed correctly the first attempted table, First correct table time $_{i}$ measures the time subject $i$ spent to complete the first correct table, and the coefficients $\widehat{\alpha}_{0}, \widehat{\alpha}_{1}, \widehat{\alpha}_{2}$ and $\widehat{\alpha}_{3}$ are estimated with the following linear panel regression using data from the baseline treatment:

\section{Number of correct tables $i_{i t}=\alpha_{0}+\alpha_{1} \times$ (Self-reported) Math skills $s_{i}$ $+\alpha_{2} \times$ First table correct ${ }_{i}+\alpha_{3}$ First correct table time $i+\epsilon_{i t}$}

We obtain $\widehat{\alpha}_{0}=253.61$ (114.59), $\widehat{\alpha}_{1}=27.92$ (17.22), $\widehat{\alpha}_{2}=93.97$ (49.96) and $\widehat{\alpha}_{3}=-1.72$ (0.54) (robust standard errors in brackets), for a regression with $\mathrm{R}^{2}=0.27$. The difference between agents' production levels in the baseline and their estimated work task ability was less than the value of one (two) [three] correct tables in $28.5 \%(42.3 \%)[62.4 \%]$ of the cases.

We define reasonably and non-reasonably accurate goals on the basis of work task ability. Reasonably (non-reasonably) accurate goals are defined such that the difference -in absolute terms- between the goal set by the principal and the estimated work task ability of the agent is less (more) than the value of two tables. Using this criterion, $29.7 \%$ of the goals in the goal setting treatment are classified as reasonably accurate. We also report similar results using either a wider (+/-3 tables, $46.4 \%$ of reasonably accurate goals) or a narrower range $(+/-1$ table, $13.8 \%$ of reasonably accurate goals) for the definition of reasonably accurate goals. The difference between an agent's maximum and minimum levels of production in the baseline treatment was 
on average equal to 3.3 tables indicating that, on average, a goal which is within $+/-2$ or $+/-3$ tables of work task ability is likely to correspond to a normal range of values of production for a given participant. We show that the interaction term between the value of the goal and the reasonable goal dummy is positive and significant meaning that making a goal more challenging, while still being reasonable, has a positive effect on agents' production. This shows that the effect of the goal setting treatment on production directly lies on the selection of goals in line with our theoretical model.

TABLE O6. Linear panel regressions for production as a function of goals (Goal setting treatment).

\begin{tabular}{|c|c|c|c|}
\hline \multirow[t]{2}{*}{ Goal setting treatment } & \multicolumn{3}{|c|}{ Reasonable goals in: } \\
\hline & $+/-1$ table & $+/-2$ tables & $+/-3$ tables \\
\hline Constant & $\begin{array}{c}338.81 * * * \\
(55.48)\end{array}$ & $\begin{array}{c}344.01 * * * \\
(57.29)\end{array}$ & $\begin{array}{c}336.33 * * * \\
(54.42)\end{array}$ \\
\hline Goal Value ( $\phi)$ & $\begin{array}{l}-0.03 \\
(0.07)\end{array}$ & $\begin{array}{l}-0.04 \\
(0.08)\end{array}$ & $\begin{array}{l}-0.05 \\
(0.08)\end{array}$ \\
\hline Reasonable Goal Dummy ${ }^{\dagger}$ & $\begin{array}{c}-127.44 * * \\
(63.49)\end{array}$ & $\begin{array}{c}-134.50 * * * \\
(46.25)\end{array}$ & $\begin{array}{l}-71.86^{*} \\
(37.68)\end{array}$ \\
\hline Reasonable Goal Dummy $\times$ Goal Value $(\phi)$ & $\begin{array}{l}0.40^{*} \\
(0.22)\end{array}$ & $\begin{array}{c}0.39 * * * \\
(0.14)\end{array}$ & $\begin{array}{l}0.20^{*} \\
(0.11)\end{array}$ \\
\hline \multicolumn{4}{|l|}{ Contract offer } \\
\hline$\overline{\text { Performance pay }}$ & $\begin{array}{l}1.64^{*} \\
(0.97)\end{array}$ & $\begin{array}{l}1.66^{*} \\
(1.02)\end{array}$ & $\begin{array}{l}1.84^{*} \\
(0.98)\end{array}$ \\
\hline Number of observations & 138 & 138 & 138 \\
\hline $\mathrm{R}^{2}$ & 0.04 & 0.06 & 0.05 \\
\hline$\chi^{2}$ & $12.66 * *$ & $14.99 * * *$ & $9.72 * *$ \\
\hline
\end{tabular}

\section{O.2.2. On the "piling-up" effect of goal setting}

In Figure E1 we show the cumulative distribution function for production on the work task. We observe that production levels are more concentrated in the goal setting treatment than in the baseline. The standard deviation of production and the coefficient of variation are significantly lower in the goal setting treatment $(\mathrm{SD}=148.4, \mathrm{CV}=0.36)$ than in the baseline $(\mathrm{SD}=179.2, \mathrm{CV}$ $=0.55)(F(122,114)=1.46, p$-value $=0.04)$. This result is consistent with previous goal setting theoretical works (e.g. Wu et al. 2008, Section 4, pages 15-19) finding that production "piles up" around the goal implying that goal setting decreases the dispersion in production. 


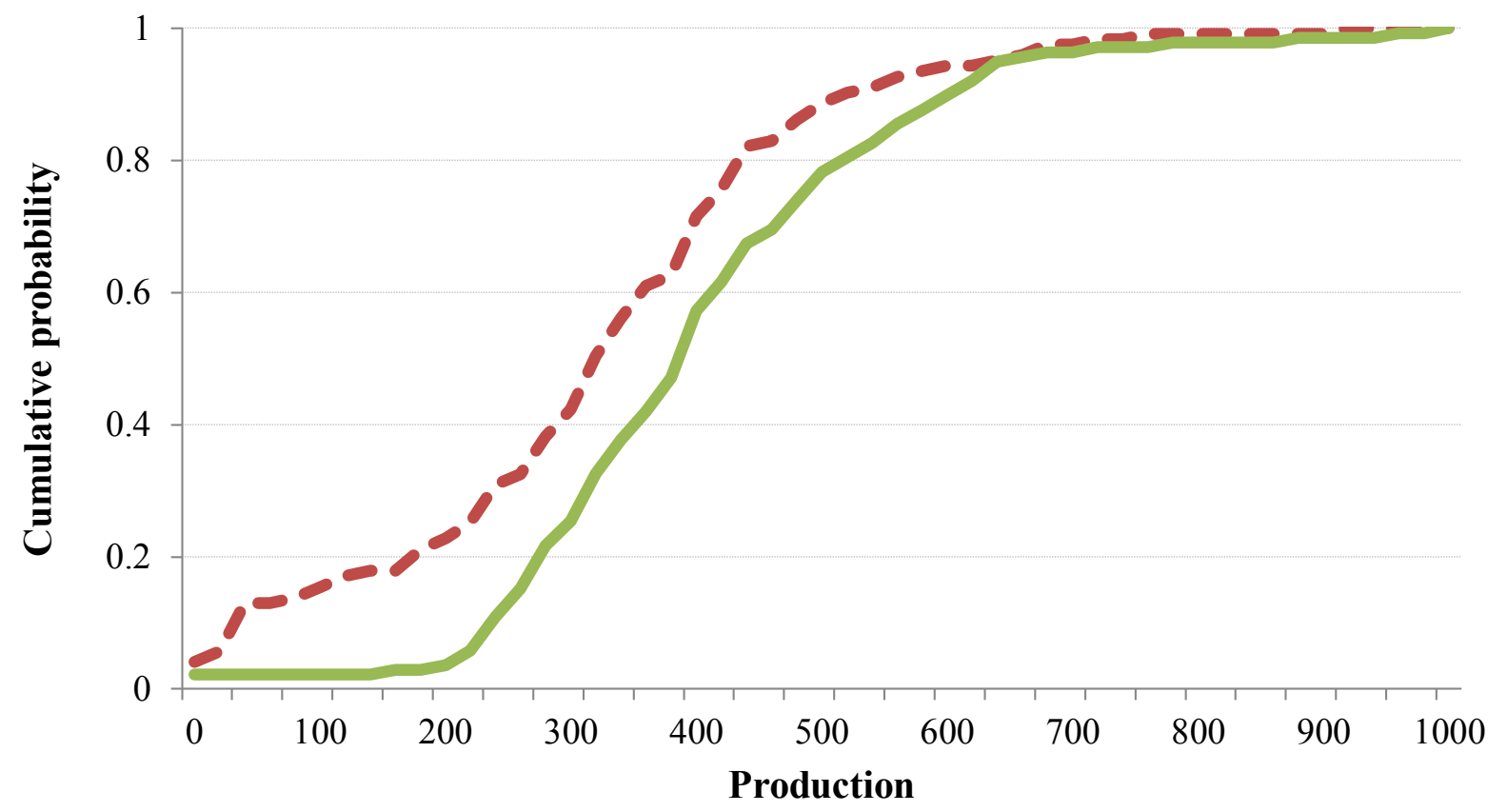

- Baseline Goal Setting

Figure O1. Cumulative distribution functions for production by treatment.

Figure $\mathrm{O} 1$ also shows that the difference in production across treatments is particularly large for low production levels. A significant proportion of agents (21.1\%) produced less than $200 \varnothing$ per period in the baseline, whereas these low levels of production are almost non-existent in the goal setting treatment $(2.9 \%$, Proportion test, $p$-value $<0.01)$. Thus, goal setting seems to be especially effective motivating agents who would have produced very little in an environment with only monetary incentives. 